\section{Hydrolyzed Casein Reduces Browsing of Trees and Shrubs by White-tailed Deer}

\author{
Bruce A. Kimball ${ }^{1}$ and Dale L. Nolte \\ U.S. Department of Agriculture, Wildlife Services, National Wildlife Research \\ Center, 4101 LaPorte Avenue, Fort Collins, CO 80521
}

\author{
Kelly B. Perry \\ U.S. Department of Agriculture, Wildlife Services, National Wildlife Research \\ Center, 9730-B Lathrop Industrial Drive, Olympia, WA 98512
}

Additional index words. foraging behavior, protein avoidance, repellent, wildlife damage

\begin{abstract}
Hydrolyzed casein (HC) and retail products that contain $\mathrm{HC}$ are evaluated as repellents to minimize deer damage to trees and shrubs. Three different experiments demonstrate that $\mathrm{HC}$ is an effective deer repellent. Technical-grade $\mathrm{HC}$ completely eliminated browse damage to evergreen shrubs (Gaultheria shallon Pursh.) and conifers (Thuja plicata Donn.) during the test periods. Retail sources of HC (concentrated baby formula powders) are not as effective as pure hydrolyzed protein, but do offer browse protection when alternative sources of browse are available. For nursery, orchard, and reforestation applications, $\mathrm{HC}$ is a promising deer repellent to minimize losses due to browse. For the private homeowner, a simple repellent formulated with glue and a $\mathrm{HC}$-containing baby formula may offer considerable browse protection when alternative forage is available.
\end{abstract}

Damage to horticultural resources by deer has been recognized as a substantial economic problem for some time (Wywialowski, 1998); with no indication that the problem is subsiding. Vegetable, fruit, and nut producers reported a $17 \%$ increase in crops lost to ungulates in the late 1990s compared to a decade earlier (Wywialowski, 1998). Beyond immediate loss of plant tissues, deer browse damage also reduces the future value of these commodities via decreased yields and plant deformities (Nolte, 1998). Fear of browse damage may potentially result in reduced tree and shrub purchases by homeowners (Lemieux et al., 2000). However, browse damage is not limited to commercial agriculture, reforestation efforts, and private landscape. High rates of deer browsing to ginseng have recently been implicated in the decline of wild populations and suggest the possible extinction of valuable forest understory herbs (Mcgraw and Furedi, 2005). Nor is the wide-ranging problem of deer browse damage to valuable plants limited to North America. Increased agricultural losses due to deer browse are also reported in Europe (Santilli et al., 2004).

A number of commercially available repellents containing a broad range of active ingredients are used to deter browsing of trees and shrubs by deer. Most of these products must be topically applied onto the plants to confer protection. Among these contact re-

Received for publication 6 May 2005. Accepted for publication 28 June 2005. The authors thank Jorge Vivanco and Julie Mennella for their helpful reviews of the manuscript. Tactic sticker/spreader was provided by Loveland Products, Inc., Greeley, Colo. Mention of specific products does not constitute endorsement by the United States Department of Agriculture. A portion of this research was funded by USDA-CSREES-IFAFS Program Code 14.1: Alternative Natural Resource Management Practices for Private Lands Grant 2001-52103-11215.

${ }^{1}$ To whom reprint requests should be addressed; e-mail bruce.a.kimball@aphis.usda.gov. pellents, four different modes of action have been proposed: flavor aversion learning (FAL), taste modification, chemical irritation, and fear (Nolte and Wagner, 2000). The fact that effective repellents share the requirement of direct contact with the target plant suggests that all four modes of action may be unified. We suggest that palatability is this central mechanism. Palatability of foods is determined by integration of the flavor of the food and the postingestive consequences that occur from its consumption (Provenza, 1995a).

Repellents that use FAL cause repellency via a toxin that produces negative postingestive consequences. Animals that ingest foods treated with the toxin form aversions to the food via associative learning (Provenza, 1995a). Some repellents negatively impact plant palatability through the use of bitter agents, e.g., denatonium benzoate. However, a number of studies have demonstrated that products which rely on bitter taste as the sole mode of action are not effective repellents (Nolte and Wagner, 2000). Other repellents impact palatability by causing irritation to the eyes, nose, and mouth of the herbivore (e.g., capsaicin or hot pepper). Low concentrations of capsaicin, such as those found in many commercial repellents, do not always deter deer browsing (Andelt et al., 1994). However, this same study also demonstrated that concentrations approaching those found in food-grade hot sauces can significantly reduce deer browsing.

Repellents using animal tissues (e.g., blood, rotten egg) or predator odors (e.g., urine) as active ingredients are thought to following a 6-h food deprivation. elicit predator avoidance behavior in herbivores (Mason, 1998). This mechanism has been anthropomorphically labeled fear (Nolte and Wagner, 2000). The predator avoidance mechanism assumes that herbivores interpret volatile sulfur compounds resulting from the degradation of animal proteins and volatile fatty acids resulting from lipid degradation as indicators of predator activity. However, the predator avoidance mechanism can not account for acceptance of untreated plant parts found immediately adjacent to plant tissues treated with animal tissue-based repellents (Kimball and Nolte, 2005). Though volatile compounds may serve as cues to warn herbivores that an unpalatable protein is present, selective browsing of untreated parts suggests that herbivores are not avoiding predators when they avoid treated plants.

We recently demonstrated that certain animal proteins (milk casein and egg albumen) significantly reduced browsing of a preferred conifer by black-tailed deer (Kimball and Nolte, 2005). A nonanimal protein source, soy, also reduced deer browsing; though not as impressively as casein and albumen. Conversely, porcine collagen (both acid and base hydrolyzed) did not prevent deer browse. We concluded that avoidance of plants treated with certain proteins is mediated through changes in the palatability of the treated food source. In particular, proteins that contain methionine significantly alter palatability and restrict deer intake of treated plants (Kimball and Nolte, 2005).

We conducted several experiments toward development of a new repellent to minimize deer browsing to commercial and ornamental plants. One experiment was designed to determine relative deer avoidance of an intact methionine-containing protein (casein) versus the same protein after hydrolysis [hydrolyzed casein (HC)]. A second experiment examined the ability of HC products to deter deer browsing of a preferred shrub (Gaultheria shallon Pursh.) and compared two methods to adhere the products to the shrub. The final experiment examined the efficacy of HC repellents applied to western redcedar (Thuja plicata Donn.) saplings over a 3-week period.

\section{Materials and Methods}

Subjects and facilities. Captive 2- to 4-year old, hand-reared white-tailed deer(Odocoileus virginianus ochrourus) were used for all experiments. Subjects were used in multiple experiments and group housed in a 2-ha outdoor pen when not being tested. Shelter and ad libitum water and mineral block were provided for all experiments. Access to pelleted basal rations was ad libitum for all experiments except Expt. 1 when access was denied for $6 \mathrm{~h}$ before

Table 1. Design of Expt. 1. Base (B), casein (HC), and hydrolyzed casein (HC) were offered for 30 min

\begin{tabular}{llll}
\hline Phase & Subject & Days & Diet \\
\hline Initial experience & 12 & $1-16$ & B, C, HC (three choices) \\
One-choice & 6 & $17-24$ & C (one-choice) \\
& 6 & $17-24$ & HC (one-choice) \\
Postexposure & 12 & $25-32$ & B, C, HC (three-choice) \\
\hline
\end{tabular}


testing. Daily 30-min feeding tests of Expt. 1 were conducted in sheltered individual outdoor pens $(2.5 \times 5.0 \mathrm{~m})$, whereupon subjects were returned to the large outdoor pen.

Experiment 2 was conducted in five 0.2 -ha outdoor pens. Natural vegetation was sparse in these pens. Experiment 3 was conducted in five 2.0-ha outdoor pens with considerable natural cover and some natural browse sources. The experiments described here were conducted during the period of May 2004 to April 2005 and approved by the Institutional Animal Care and Use Committee of the USDA National Wildlife Research Center.

Experiment 1. Experiment 1 was conducted in three phases (Table I). The first (initial experience) was designed to determine the test subjects' preference for foods adulterated with casein and HC. The second phase (one-choice) was conducted to determine if subjects would consume casein and $\mathrm{HC}$ adulterated foods when no alternatives were available. The final phase (postexposure) consisted of a preference test, identical to the initial experience phase, to evaluate if one-choice exposure to casein and HC-treated foods influenced preferences of the treated diets.

The base diet consisted of a mixture of 6.0 $\mathrm{kg}$ cracked corn, $13.0 \mathrm{~kg}$ dried ground alfalfa, $5.0 \mathrm{~kg}$ sugar beet pulp, and $1.0 \mathrm{~L}$ vegetable oil. Casein or $\mathrm{HC}$ (2.75 kg each; American Casein Co., Burlington, N.J.) was added to $25.0 \mathrm{~kg}$ base diet to yield a concentration of $10 \%$ for each test diet. The manufacturer reports casein to be $90 \%$ protein and contain $2.5 \%$ methionine; $\mathrm{HC}$ contains $86 \%$ protein with $2.7 \%$ methionine.

Before the initial experience phase, 15 subjects were offered $200 \mathrm{~g}$ of base diet daily for $4 \mathrm{~d}$ in one-choice adaptation tests. Feeding trials were conducted each afternoon at 1400 HR for 30 min following a 6 -h food deprivation. Following adaptation, subjects were assigned to one of two treatment groups (casein or $\mathrm{HC}$; six subjects per treatment) such that mean base diet intake and standard deviation were similar between treatments. Three subjects were removed from Expt. 1 on the basis of low base diet consumption.

In the initial experience phase, all subjects were offered $200 \mathrm{~g}$ each of base (B diet), casein (C diet), and $\mathrm{HC}$ ( $\mathrm{HC}$ diet) diets in three-choice tests for 30 min following a 6 -h food deprivation (Table 1). The positions of the foods (left, center, right) were randomly assigned. The initial experience phase lasted $16 \mathrm{~d}$ and was followed immediately by the one-choice phase. Subjects in the one-choice phase were offered $\mathrm{C}$ diet or $\mathrm{HC}$ diet only (according to treatment assignment) following similar procedures as the initial experience phase (Table 1). Onechoice offering of $\mathrm{C}$ diet or $\mathrm{HC}$ diet lasted for $8 \mathrm{~d}$ and was immediately followed by the postexposure preference test. As in the initial experience phase, deer preference for $\mathrm{B}, \mathrm{C}$, and $\mathrm{HC}$ diets was determined by three-choice test (Table 1). The postexposure preference test was conducted for $8 \mathrm{~d}$.

Consumption data from each phase of Expt. 1 were subjected to separate mixed model analyses of variance (ANOVA). Intake (g) was the response for each analysis with subject (nested in treatment), day $\times$ subject(treatment), and diet $\times$ subject(treatment) the random effects. Diet (B, C, or HC diet), day, and treatment were the main effects and all higher order interactions were considered. Multiple comparisons among treatments were made with the PDIFF option to the least-square means (proc MIXED; SAS, 2002) and applying a sequential Bonferoni correction (Rice, 1989). Consumption during the one-choice phase was similarly analyzed to examine treatment differences except that diet effect was not necessary for the model. A fourth analysis was used to compare intake between the initial experience and postexposure phases by incorporating a new fixed effect (phase) and not considering the day effect.

Experiment 2. Salal (Gaultheria shallon) shoots (five leaves per shoot) were offered to deer by stapling them to a horizontal wooden bracket. The bracket was built with 2 -inch $\times$ 4 -inch $\times 8$-ft building materials (i.e., studs) in a fashion resembling a soccer or hockey goal with the $2.5 \mathrm{~m}$ crossbar about $1 \mathrm{~m}$ off the ground. In each 0.2-ha pen, five brackets were placed in a line (parallel to each other) spaced at 2-m intervals. Treatments were randomly assigned to the brackets at the beginning of the experiment. All 12 plant shoots on a bracket were treated identically. For cohort A, salal shoots were sprayed with a solution of $0.26 \%$ agricultural latex sticker (Tactic, Loveland Products, Inc. Greeley, Colo.) in water with a garden-type tank sprayer and immediately dusted with one of four test substances. A kitchen apparatus (grated-cheese shaker) was used to sprinkle the dry powders. The fifth treatment consisted of the sticker only.
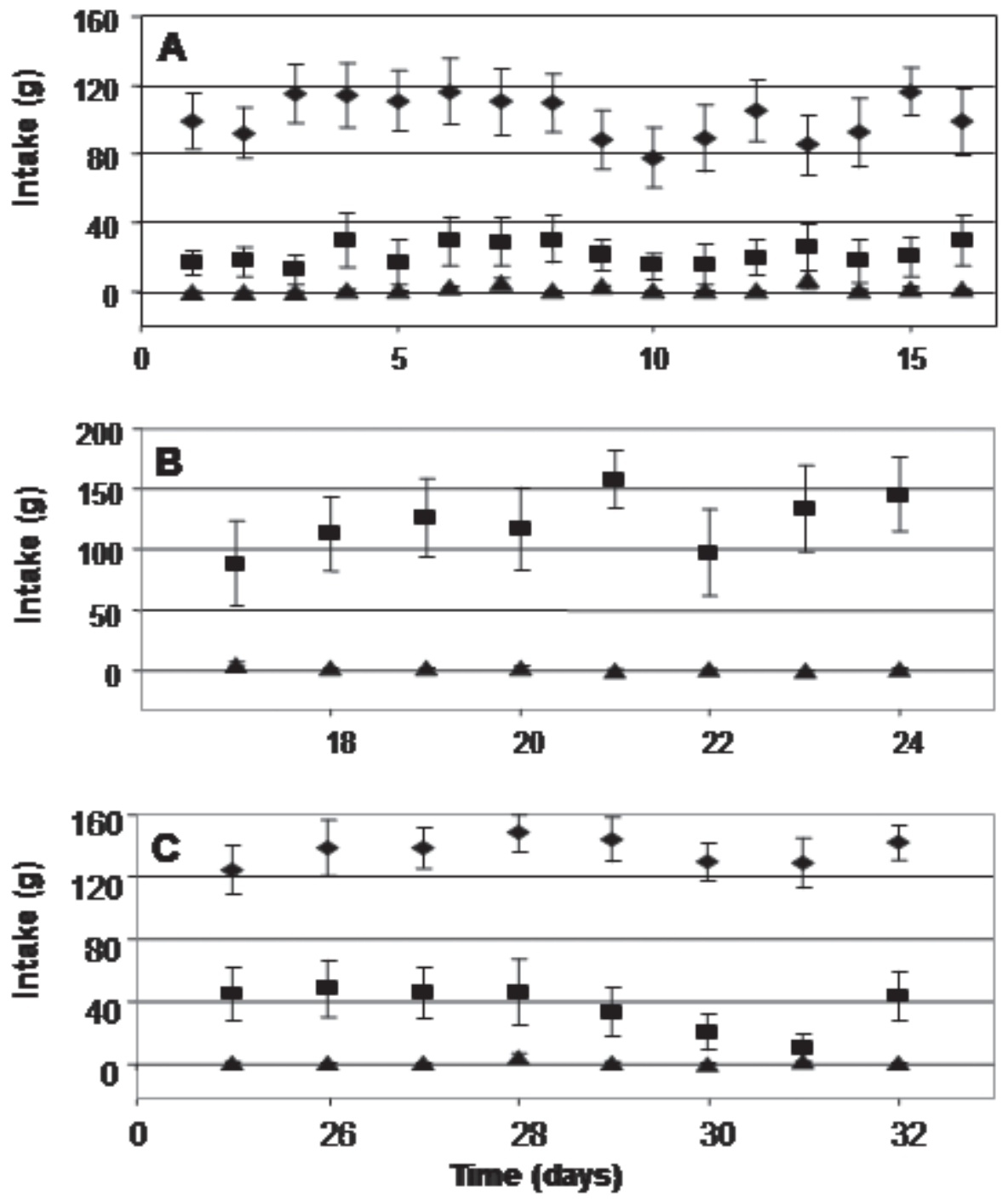
The test substances were Deer-Away Big Game Repellent powder (BGR-P; IntAgra, Inc., Minneapolis, Minn.), HC, and two HC-containing concentrated powdered baby formulas (Formulas A and B). Three subjects were assigned to each pen and confined to the pen for the duration of Expt. 2.

The number of leaves removed from each shoot was monitored at 3, 6, 24, 48, and $72 \mathrm{~h}$. After $72 \mathrm{~h}$, all remaining shoots were removed and replaced with fresh salal shoots. The experiment was repeated (cohort B) by spraying the shoots with a solution of $0.26 \%$ Elmer's Glue All (Elmer's Products, Columbus, Ohio) in water and immediately dusting with one of the test substances. The fifth treatment was the glue sticker alone. Treatment, subject, and pen assignments in cohort B were identical to A.

A Kaplan-Meier survival analysis was

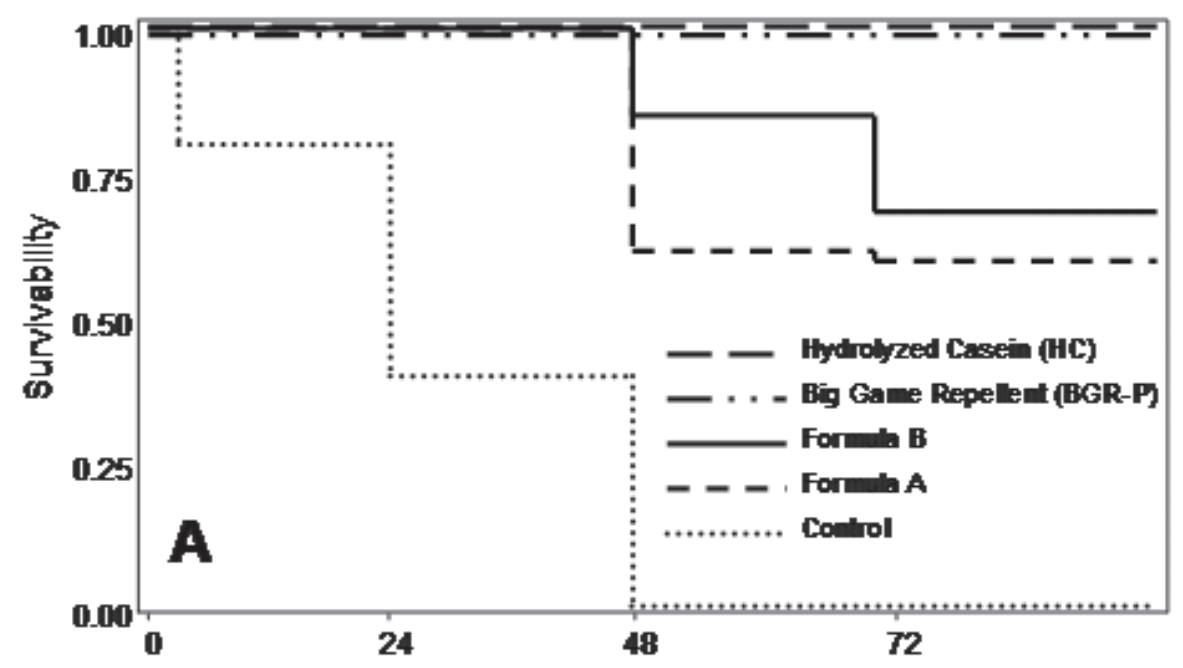

Failure Trme (Hous)

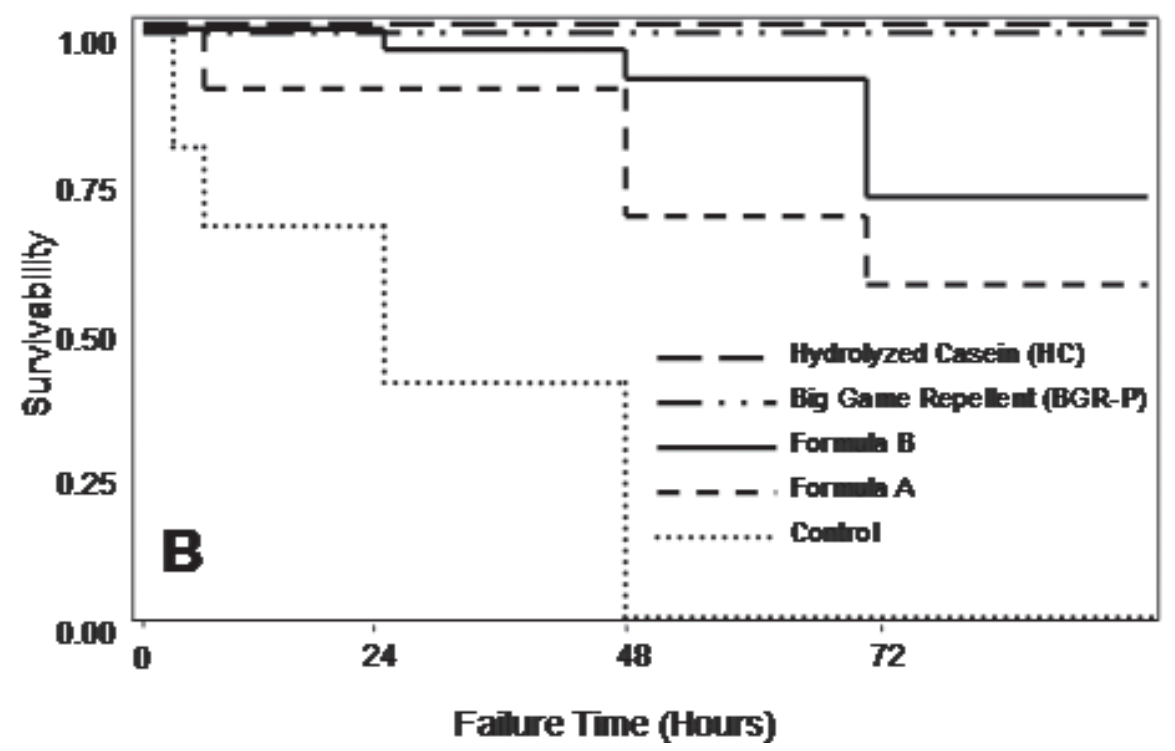

Fig. 2. Survivability functions obtained from salal (Gaultheria shallon) shoots treated with different sources of hydrolyzed casein in Expt. 2. (A) Treatments using Tactic latex sticker/spreader. (B) Treatments using Elmer's Glue All as the sticker. Hydrolyzed casein (HC, _- - ), Big Game Repellent (BGR-P, -

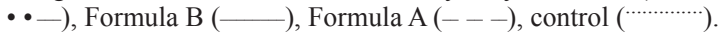

western redcedar saplings (about $30 \mathrm{~cm}, 2$-yearold nursery stock) were planted in five unique plots. Within a plot, 12 trees were arranged in a $3 \times 4$ arrangement (spaced $1 \mathrm{~m}$ apart) while plots were separated by at least $3 \mathrm{~m}$. Treatments were applied similar to Expt. 2 by spraying individual trees uniformly with 0.26 Elmer's Glue-All solution in water and dusting with the four powder treatments. For this experiment, $5 / 16$ inch holes were drilled into the plastic lids of discarded baby formula containers to serve as shaker devices. The control consisted of the sticker alone. Except where replaced, identical subjects from Expt. 2 were maintained in their previous combinations of three and confined to the appropriate pen for the duration of the experiment $(20 \mathrm{~d})$. The number of bites on each tree was recorded on days 1, 2, 3, 5, 7, $9,12,14,16$, and 20 until the individual tree was completely consumed (defined as 25 bites). Severe browse damage was defined as 10 cumulative bites to an individual tree.

Similar to Expt. 2, bite data was used to define failure, i.e., that day when severe browse damage (10 bites) was first recorded. If $<10$ bites were recorded on day 20 , failure was defined as day 25 and the tree was censured for Kaplan-Meier analysis. Rank data generated from failure day ( $1=$ shortest failure day) was subjected to Kruskal-Wallis analysis as in Expt. 2 except that there was no cohort effect.

\section{Results}

Experiment 1. Diet $(p<0.0001)$ and day $(p=0.0117)$ were the only significant effects of the initial experience phase of Expt. 1 (Fig. 1A). Examination of the least-square diet means indicates that $\mathrm{B}$ diet intake (122 g) was significantly greater than both $\mathrm{C}$ diet (26.8 g; $p<0.0001)$ and $\mathrm{HC} \operatorname{diet}(1.75 \mathrm{~g} ; p<$ 0.0001 ). The difference between $\mathrm{C}$ and $\mathrm{HC}$ diet consumption was only moderately significant $(p=0.0916)$.

Due to day to day variation of $\mathrm{C}$ diet consumption, treatment $\times$ day interaction was significant during the one-choice phase ( $p=$ 0.0150 ; Fig. 1B). However, C diet intake (123 g) was greater than $\mathrm{HC}$ diet (1.90 g) on each day $(p=0.0021)$. Postexposure preference data were very similar to the initial experience phase (Fig. 1C). Diet $(p<0.0001)$ and day ( $p=$ 0.0282 ) were the only significant effects. Base diet intake $(137 \mathrm{~g})$ was significantly greater than both $\mathrm{C} \operatorname{diet}(36.8 \mathrm{~g} ; p<0.0001)$ and $\mathrm{HC}$ $\operatorname{diet}(1.35 \mathrm{~g} ; p<0.0001)$. Consumption of $\mathrm{C}$ diet was significantly greater than $\mathrm{HC}$ diet $(p$ $=0.0195$ ).

Analysis of combined data from initial and postexposure phases further demonstrated that preferences were not influenced by one-choice exposure. Although diet $(p<0.0001)$, phase $(p=0.0221)$, and diet $\times$ phase $(p=0.0050)$ effects were significant, treatment $\times$ phase $(p$ $=0.4189)$ and treatment $\times$ diet $\times$ phase $(p=$ 0.1402 ) interactions were not.

Experiment 2. One deer subject from cohort B was lost due to mortality and not replaced. Another subject (from a different pen assignment) was removed from cohort B due to behavioral concerns and not replaced. Kaplan- 


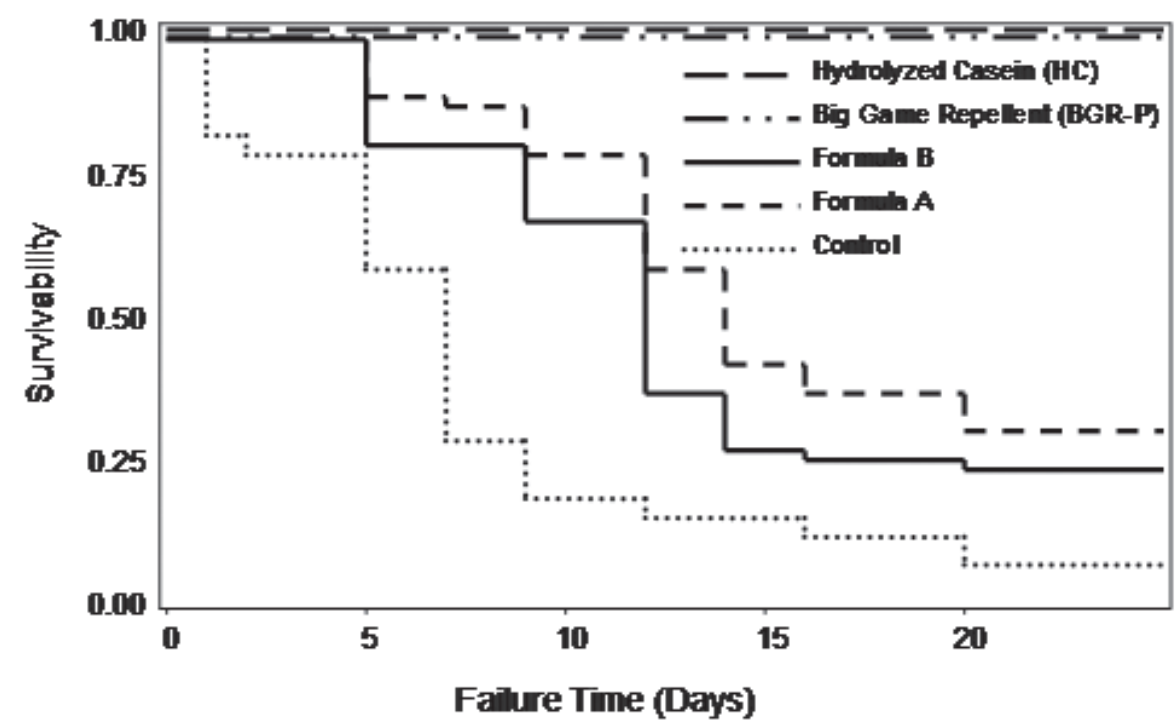

Fig. 3. Survivability functions obtained from western redcedar (Thuja plicata) saplings treated with different sources of hydrolyzed casein in Expt. 3. Hydrolyzed casein (HC, - - ), Big Game Repellent (BGR-P, $-\cdots-)$, Formula B (-), Formula A $(---)$, control (………).

Meier survival analyses demonstrated that survivability functions differed significantly among treatments in cohort $\mathrm{A}(p<0.0001$; Fig. 2A) and cohort B ( $p<0.0001$; Fig. 2B). Survival of salal shoots treated with BGR-P and $\mathrm{HC}$ exhibited complete (100\%) survival in both cohorts. No control shoots survived in either cohort.

Survivability of baby formula-treated shoots ranged from $57 \%$ to $72 \%$ depending on the treatment and cohort (Fig. 2A and B). Pen by pen inspection of cohort A data indicated that no leaves were removed from a treated shoot until all control shoots were completely browsed in the pen. Furthermore, $100 \%$ survival of baby-formula-treated shoots was observed in three of the five pens. Similar results were evident in cohort $\mathrm{B}$, except for a single pen where eight formula-treated shoots were partially browsed before the 12 control shoots were completely browsed and $100 \%$ survival of formula-treated shoots occurred in only two of the pens.

Kruskal-Wallis analysis of the ranked data demonstrated no cohort ( $p=1.000$ ) or cohort $\times$ treatment interaction $(p=0.9212)$. However, there was a significant treatment effect $(p<$ 0.0001). Multiple comparisons of the means indicated that failure rank follows the order of $\mathrm{HC}=$ BGR-P $>$ Formula $\mathrm{A}=$ Formula $\mathrm{B}$ $>$ Control, with HC and BGR-P offering the greatest protection from deer browse and control the least.

Experiment 3. Kaplan-Meier survival analyses demonstrated that survivability functions differed significantly among treatments $(p$ $<0.0001$; Fig. 3). No individual trees treated with HC or BGR-P suffered severe browse. In fact, only eight total bites were counted on the 120 trees treated with HC or BGR-P. As in Expt. 2, no bites were recorded to formulatreated treated trees until all 12 control trees in the pen were completely consumed (about 25 bites). Also similar to Expt. 2, Kruskal-Wallis analysis of the ranked data demonstrated a significant treatment effect $(p<0.0001)$ with multiple comparisons of the means indicating that failure rank follows the identical order of $\mathrm{HC}=$ BGR-P $>$ Formula $\mathrm{A}=$ Formula $\mathrm{B}$ $>$ Control.

\section{Discussion}

Experiment 1 demonstrates two important results for developing an effective deer repellent. First, $\mathrm{HC}$ is more effective than casein for reducing consumption of white-tailed deer. This is particularly evident in the one-choice phase of the experiment when subjects in the $\mathrm{HC}$ treatment group refused to eat HC-treated food, even when it was their only choice (Fig. 1B). Second, one-choice exposure to the treated foods did not influence postexposure preference. Specifically, B diet was still preferred in the postexposure three-choice test despite considerable consumption of $\mathrm{C}$ diet during the one-choice phase.

Together, these results suggest that $\mathrm{HC}$ is of treated plants will not necessarily render $\mathrm{HC}$ ineffective at future encounters. This is important because even the most effective contact repellents can fail to work under certain conditions. For example, BGR-P (effective in this study) can be ineffective when no alternative foods are available (Andelt et al., 1991). Even in natural systems herbivores will sometimes eat poisonous plants that produce severe negative postingestive consequences (Provenza et al., 1992). However, these same plants are avoided when encountered later in familiar environments with ample alternative food sources. Similarly, an effective deer repellent must be avoided under typical conditions even after deer are forced to consume treated plants under extreme conditions.

In addition to demonstrating that $\mathrm{HC}$ reduces deer consumption of a preferred shrub and a conifer, Expts. 2 and 3 indicate that retail $\mathrm{HC}$-containing baby formulas provide browse protection when alternative plants (controls) are available. In cohort A of Expt. 2, formulaa promising repellent and that consumption treated plants were not browsed (if at all) until after all control plants were exhausted. Furthermore, consumption of these treatments did not extinguish avoidance of formula-treated plants in later tests. Rather, subjects continued to avoid these treatments in cohort B (Expt. 2 ) and Expt. 3 whenever control plants were available. Within each pen, no formula-treated redcedar sapling received even a single bite in Expt. 3 until all 12 control saplings were completely consumed.

Avoidance of formula-treated plants relative to untreated plants suggests that baby formulas containing $\mathrm{HC}$ may be useful deer repellents for the private homeowner and gardener. At this spatial scale, availability of alternative browse items is maximized unless all gardeners in the very heterogeneous landscape are using the same repellent. Conversely, larger-scale application of HC-based repellents (e.g., nurseries, reforestation, etc) in homogenous landscapes will require the use of technical-grade HC.

Efficacy differences among $\mathrm{HC}$ and the two baby formulas in these controlled experiments were likely due to concentration effects. Sprinkling of plants with baby formula (about 17\% HC) delivered significantly less $\mathrm{HC}$ to the plants versus sprinkling with pure, technical-grade HC. An ongoing study of HC as a repellent for reducing black-tailed deer (Odocoileus hemionus columbianus) browsing of conifer saplings is demonstrating an unambiguous positive relationship between $\mathrm{HC}$ concentration and deer avoidance (B.A. Kimball, unpublished data).

While agricultural stickers such as Tactic are specifically designed to affix active ingredients from an aqueous application to plant tissues, availability and cost of these technically advanced products render them unavailable for home garden applications. Experiments 2 and 3 demonstrated that a simple sticker, i.e., Elmer's Glue-All, is an effective method to adhere repellent powders to trees and shrubs for small-scale applications. No visible evidence of phytotoxicity was observed on western redcedar saplings sprayed with the glue solution. A simple method for applying $\mathrm{HC}$ products is to spray the plants with the dilute glue solution $(0.26 \%)$ and lightly sprinkle the wetted plant with the powder. At least two straightforward techniques can be used to deliver the powders. A kitchen apparatus (grated-cheese shaker) can be used as well as simply drilling the plastic lid of the baby formula containers with $5 / 16$ inch holes to manufacture a homemade shaker. Conversely, large-scale needs (such as reforestation applications) indicate the use of technical grade $\mathrm{HC}$ and an agricultural latex-based sticker.

The results of these experiments are consistent with the theory that methionine-containing proteins minimize deer browsing by altering the palatability of the plant (Kimball and Nolte, 2005). Furthermore, the products of protein hydrolysis are less palatable than the intact protein. This same phenomenon is observed in human infants (Mennella and Beauchamp, 1998). Infants older than 4 months reject baby formulas containing $\mathrm{HC}$ in favor of soy or 
milk-based based formulas. Interestingly, early exposure (first months of life) to $\mathrm{HC}$ formulas leads to acceptance later in human development (Mennella et al., 2004).

The captive-raised white-tailed deer in this study (as well as the mother-raised black-tailed deer in our other studies) find HC unpalatable later in development. However, had the white-tailed deer subjects been hand-reared on $\mathrm{HC}$ formula, rather than a whey-based milk replacer, their response to $\mathrm{HC}$ treatments may have been significantly different in this study.

Diet selection in herbivores is shaped by three types of memory (Provenza, 1995b). Individual experience with a food and its flavor, the social influences of mother and conspecifics, and the evolutionary genetics of the individual are significant determinants of diet selection in herbivores. Thus, a food need not cause negative consequences to the consumer to render it unpalatable. However, avoidance of a particular food is typically associated with one of these memories (Provenza, 1995b). While there is no evidence that ingestion of $\mathrm{HC}$ causes negative postingestive consequences for the individual consumer, its flavor may have a particular social or evolutionary significance that produces avoidance. We submit that deer avoidance of $\mathrm{HC}$ and other methioninecontaining proteins may result from such an evolutionary memory.

\section{Literature Cited}

Andelt, W.F., K.P. Burnham, and D.L. Baker. 1994. Effectiveness of capsaicin and bitrex repellents for deterring browsing by captive mule deer. J. Wildlife Mgt. 58:330-334.

Andelt, W.F., K.P. Burnham, and J.A. Manning. 1991. Relative effectiveness of repellents for reducing mule deer damage. J. Wildlife Mgt. 55:341-347.

Kimball, B.A. and D.L. Nolte. 2005. Animal tissuebased herbivore repellents: Scary odors or altered palatabilty? In: C. Feare and D.P. Cowan (eds.). Advances in vertebrate pest management: Proc. 4th European vertebrate pest Conf. (in press).

Lemieux, N.C., B.K. Maynard, and W.A. Johnson. 2000. Evaluation of commercial deer repellents on ornamentals in nurseries. J. Environ. Hort. 18:5-8.

Mason, J. R. 1998. Mammal repellents: Options and considerations for development. In: R.O. Baker and A.C.Crabb (eds.). Proc. 18th Vertebrate Pest Conf. 18:325-329

Mcgraw, J.B. and M.A. Furedi. 2005. Deer browsing and population viability of a forest understory plant. Science 307:920-922.

Mennella, J.A. and G.K. Beauchamp. 1998. Development and bad taste. Pediatric Asthma Allergy Immunol. 12:161-163.

Mennella, J.A., C.E. Griffin, and G.K. Beauchamp. 2004. Flavor programming during infancy.
Pediatrics 113:840-845.

Nolte, D.L. 1998. Efficacy of selected repellents to deter deer browsing on conifer seedlings. Int. Biodeterior. Biodegrad. 42:101-107.

Nolte, D.L. and K.K. Wagner. 2000. Comparing the efficacy of delivery systems and active ingredients of deer repellents. In: T.P. Salmon and A.C.Crabb (eds.). Proc. 19th Vertebrate Pest Conf. 19:93-100

Provenza, F.D. 1995a. Postingestive feedback as an elementary determinant of food preference and intake in ruminants. J. Range Mgt. 48:2-17.

Provenza, F.D. 1995b. Tracking variable environments-There is more than one kind of memory. J. Chem. Ecol. 21:911-923.

Provenza, F.D., J.A. Pfister, and C.D. Cheney. 1992. Mechanisms of learning in diet selection with reference to phytotoxicosis in herbivores. J. Range Mgt. 45:36-45.

Rice, W.R. 1989. Analyzing tables of statistical tests. Evolution 43:223-225.

Santilli, F., L. Mori, and L. Galardi. 2004. Evaluation of three repellents for the prevention of damage to olive seedlings by deer. Eur. J. Wildl. ife Res. 50: 85-89.

SAS Institute Inc. 2002. SAS/STAT. Version 9.1. SAS Ins., Cary, N.C.

Wywialowski,A.P. 1998. Are wildlife-caused losses of agriculture increasing? In: R.O. Baker and A.C. Crabb (eds.). Proc. 18th Vertebrate Pest Conf. 18:363-370. 